\title{
Đánh giá mức độ nhiễm và dặc điểm kháng kháng sinh của Salmonella spp. phân lập từ thủy hải sản tươi sống tại các chọ truyển thống trên địa bàn thành phố Hổ Chí Minh
}

Truơng Huỳnh Anh Vü ${ }^{1,2^{\star}}$, Nguyễn Hoàng Khuê Tú ${ }^{3}$, Huỳnh Yên Hà', Chu Vân Hải ${ }^{1}$ ${ }^{1}$ Phòng Vi sinh, Trung tâm Dịch vụ Phân tích Thí nghiệm thành phố Hồ Chí Minh, Việt Nam ${ }^{2}$ Khoa Khoa học Sinh học, Truờng Đại học Nông Lâm thành phố Hồ Chí Minh, Việt Nam ${ }^{3} B \hat{o}$ môn Công nghệ Sinh học, Trường Đại học Quốc tế, Đại học Quốc gia thành phố Hồ Chí Minh, Việt Nam

(Ngày đến tòa soạn: 12/01/2021; Ngày chấp nhận đăng: 10/03/2021)

\section{Tóm tắt}

Trong nghiên cứu này, tổng số 380 mẫu thủy hải sản (tôm, cá, mực) tươi sống đã được lấy ngẫu nhiên tại các chợ truyền thống thuộc các quận trên địa bàn thành phố Hồ Chí Minh. Tiến hành định tính Salmonella spp. bằng kỹ thuật nuôi cấy theo ISO 6579-1:2017, chọn khuẩn lạc điển hình, khẳng định bằng kỹ thuật $\mathrm{PCR}$ (TCVN 8342:2010), xác định serovar theo ISO/TR 6579-3:2014 và đánh giá đặc điểm nhạy cảm kháng sinh của chúng bằng phương pháp khuếch tán trong thạch (Kirby-Bauer). Kết quả cho thấy có 85 mẫu nhiễm Salmonella spp., tỷ lệ nhiễm là 22,37\% (85/380). Khả năng kháng kháng sinh của các chủng Salmonella spp. với ít nhất 01 loại kháng sinh chiếm 85,88\% (73/85), kháng từ 02 đến 05 loại kháng sinh 10,59\% (09/85) và từ 06 đến 11 loại kháng sinh 4,71\% (04/85). Kháng sinh có tỷ lệ vi khuẩn kháng cao nhất là tetracycline 43,53\% (37/85). Ngược lại, 98,82\% (84/85) số chủng Salmonella spp. nhạy cảm với ceftazidime. Tỷ lệ Salmonella spp. đa kháng là 15,29\% (13/85). Kiểu hình kháng kháng sinh phổ biến là ampicillin, streptomycin, tetracycline, trimethoprim/sulfamethoxazole (AM, STR, TE, SXT) chiếm 46,15\% (6/13). Định danh được 06 kiểu huyết thanh (serovar) khác nhau trong số 13 chủng Salmonella spp. đa kháng, phổ biến nhất là $S$. kentucky (05 chủng); S. infantis (02 chủng); S. agona và $S$. potsdam (01 chủng); S. saintpaul, S. braenderup (01 chủng). Kết quả phát hiện 92,31\% kiểu huyết thanh (serovar) có mang gen để kháng (blaTEM, strA: 53,85\%; blaSHV: 7,69\%; tetA: 92,31\%; tetB: 7,69\% và sul1: 23,08\%). Chỉ có 03 kiểu huyết thanh (serovar) có kiểu gen (blaTEM, strA, tetA, sul1) trùng khớp với kiểu hình để kháng (AM, STR, TE, SXT) đó là $S$. kentucky (02) và S. saintpaul (01) đều được phân lập từ mẫu cá.

Tư khóa: đa kháng; kháng kháng sinh, Salmonella, thủy hải sản.

\section{1. ĐẶT VẤN ĐỀ}

An toàn thực phẩm là một trong những vấn để mà từ lâu chúng ta đặc biệt quan tâm, được xem là yếu tố có ý nghĩa lớn về kinh tế-xã hội, sức khỏe cộng đông, ảnh hưởng trực tiếp đến mục tiêu phát triển bền vững của quốc gia. Đặc biệt là tình trạng nhiễm khuẩn kháng kháng sinh trong các sản phẩm thủy hải sản tươi sống, trong đó có vi khuẩn Salmonella spp. Nguyên nhân của hiện trạng này là do việc sử dụng kháng sinh trong nuôi trồng và điều trị bệnh chưa được kiểm soát hiệu quả. Hiện nay, sử dụng kháng sinh không đúng cách và lạm dụng trong nuôi trồng góp phân dẫn đến tình trạng vi khuẩn đề kháng kháng sinh trầm trọng như hiện nay. Để 
kiểm soát thực trạng này, các cơ quan chức năng, quản lý nhà nước đã và đang thực hiện nhiều giải pháp khác nhau, nhiêu văn bản quy phạm pháp luật được ban hành, cập nhật để quản lý việc sử dụng kháng sinh trong nuôi trồng thủy sản tốt hơn. Các chương trình theo dõi giám sát mức độ đề kháng kháng sinh của vi khuẩn trong thực phẩm cũng được thực hiện thường xuyên. Nghiên cứu này được thực hiện nhằm đánh giá (i) mức độ vấy nhiễm và (ii) thực trạng đề kháng kháng sinh nhóm $\beta$-lactam của vi khuẩn Salmonella spp. phân lập từ thủy hải sản tươi sống tại các chợ truyền thống trên địa bàn thành phố Hồ Chí Minh.

Kết quả nghiên cứu sẽ góp phần hoàn thiện các dẫn liệu khoa học về tình hình vấy nhiễm và đặc điểm kháng kháng sinh của Salmonella spp. phân lập từ thủy hải sản tươi sống, bổ sung bằng chứng khoa học cho các quyết định cấp nhà nước về quản lý và nâng cao ý thức sử dụng kháng sinh có hiệu quả tại Việt Nam nói chung và thành phố Hồ Chí Minh nói riêng.

\section{VẠT LIỆU VÀ PHƯỠNG PHÁP NGHIÊN CỨU}

\section{1. Đối tượng nghiên cứu}

Các chủng Salmonella spp. phân lập từ thủy hải sản tươi sống tại các chợ truyên thống trên địa bàn thành phố Hồ Chí Minh.

\subsection{Phương pháp nghiên cứu}

\subsubsection{Cõ̃ mẫu nghiên cứu}

Nghiên cứu sử dụng công thức tính cỡ mẫu sau:

$$
n=\frac{z^{2}(p \cdot q)}{e^{2}}
$$

Trong đó:

z: giá trị phân phối tương ứng với độ tin cậy 95\% thì giá trị z là 1,96;

p: tỷ lệ \% vớc tính của thực phâm không đạt chỉ tiêu vi sinh của một nghiên cứu trước đó, $p=0,4$ (với tỷ lệ thực phẩm không đạt chỉ tiêu vi sinh là 43,75\%);

e: múc chính xác mong muốn là 0,05 [5].

Cỡ mẫu cần cho nghiên cứu phải lớn hơn hoặc bằng 376 mẫu thực phẩm.

\subsubsection{Phương pháp lấy và bảo quản mẫu}

Tổng số 380 mẫu thủy hải sản (tôm: 219; cá: 97; mực: 64) đã được lấy ngẫu nhiên tại các chợ truyền thống thuộc các quận trên địa bàn thành phố Hồ Chí Minh vào khoảng thời gian từ 08 đến 09 giờ sáng trong suốt 12 tháng (09/2019 - 09/2020). Lượng mẫu được lấy phục vụ nghiên cứu khoảng $150 \mathrm{~g}-1.500 \mathrm{~g} / \mathrm{mẫu} \mathrm{[11].} \mathrm{Mẫu} \mathrm{được} \mathrm{chuyển} \mathrm{đến} \mathrm{phòng} \mathrm{thí} \mathrm{nghiệm} \mathrm{không}$ quá 12 giờ sau khi lấy và được tiến hành phân tích ngay.

\subsubsection{Phương pháp phân lập và xác định Salmonella spp.}

Phương pháp phân lập Salmonella spp. được thực hiện theo ISO 6579-1:2017 [1], bao gồm các bước: (i) Chuẩn bị mẫu thử và tăng sinh sơ bộ: đông nhất khoảng $25 \mathrm{~g}$ mẫu thử với $225 \mathrm{~mL}$ đệm Pepton Water-BPW (Merck/1.07228) ủ ở $37^{\circ} \mathrm{C}$ trong $18 \pm 2$ giờ; (ii) Tăng sinh chọn lọc: cấy dịch tăng sinh sang canh thang Rappaport Vassiliadis medium with soya-RV 
(Merck/1.07700) $41,5^{\circ} \mathrm{C}$ trong $24 \pm 3$ giờ và canh thang Kauffmann tetrathionate novobiocin - MKTTn (Merck/1.05878) ủ ở 37 C trong $24 \pm 3$ giờ; (iii) Phân lập: cấy dịch tăng sinh chọn lọc lên môi trường thạch chọn lọc Xylose Lysine Deoxychonate agar-XLD (Merck/1.05287) và Mannitol Lysine Crystal Violet Brilliant Green agar - MLCB (Oxoid/CM0783) ủ ở 37 ${ }^{\circ} \mathrm{C}$ trong $24 \pm 3$ giờ; (iv) Khẳng định: các khuẩn lạc nghi ngờ Salmonella spp. được khẳng định bằng kỹ thuật PCR với cặp môii invA, được trình bày tại mục 2.2.6.

\subsubsection{Phương pháp đánh giá khả năng kháng kháng sinh của Salmonella spp.}

Mỗi chủng Salmonella spp. được lấy từ 3 - 5 khuẩn lạc thuần khiết từ thạch Nutrient Agar (Merck/1.05450) để thực hiện đánh giá khả năng nhạy cảm kháng sinh bằng phương pháp Kirby-Bauer trên Muller Hinton Agar (Oxoid/CM0337). Dựa vào đường kính vùng ức chế theo hướng dẫn của CLSI [2] để phiên giải kết quả mức độ nhạy cảm kháng sinh (R/I/S) của Salmonella.

Các kháng sinh sử dụng trong nghiên cứu này được lựa chọn theo Quyết định 2625/QĐBNN-TY của Bộ Nông nghiệp và phát triển nông thôn [8]. Các đĩa kháng sinh vô khuẩn (Oxoid, Anh) có đường kính $6 \mathrm{~mm}$ được tẩm dung dịch kháng sinh với nồng độ tương ứng như sau: ampicillin (AM, $10 \mu \mathrm{g} / \mathrm{mL}$ ), amoxicillin/acid clavulanic (AMC, $30 \mu \mathrm{g} / \mathrm{mL}$ ), ceftazidime (CAZ, $30 \mu \mathrm{g} / \mathrm{mL}$ ), chloramphenicol (C, $30 \mu \mathrm{g} / \mathrm{mL}$ ), ciprofloxacin (CIP, $5 \mu \mathrm{g} / \mathrm{mL}$ ), ofloxacin (OFX, 5 $\mu \mathrm{g} / \mathrm{mL})$, gentamicin $(\mathrm{CN}, 10 \mu \mathrm{g} / \mathrm{mL})$, Streptomycin (STR, $10 \mu \mathrm{g} / \mathrm{mL}$ ), nalidixic acid (NA, $30 \mu \mathrm{g} /$ $\mathrm{mL})$, tetracycline $(\mathrm{TE}, 30 \mu \mathrm{g} / \mathrm{mL})$ và sulfamethoxazole/trimethoprim $(\mathrm{SXT}, 30 \mu \mathrm{g} / \mathrm{mL})$.

\subsubsection{Phương pháp ly trích ADN tổng số}

Dùng que cấy tròn lấy một vòng khuẩn lạc trên thạch Nutrient Agar (Merck/1.05450) cho vào Eppendorf chứa sẵn $1 \mathrm{~mL}$ nước cất vô trùng. Quy trình chiết $\mathrm{DNA}$ được thực hiện theo bộ kit AccuRive pDNA Prep Kit (KT Biotech).

\subsubsection{Phương pháp khäng định Salmonella spp. bằng kỹ thuật PCR}

Gen inv (invasion) được khuếch đại dựa trên trình tự các cặp môi đặc hiệu tương ứng được trình bày trong Bảng 1.

Thành phân hỗn hợp phản ứng PCR được thực hiện theo TCVN 8342:2010, chương trình khuếch đại trên máy Mastercycler (Eppendorf) như sau: $95^{\circ} \mathrm{C} / 5$ phút (1 chu kỳ); $95^{\circ} \mathrm{C} / 60$ giây; $54^{\circ} \mathrm{C} / 45$ giây và $72^{\circ} \mathrm{C} / 60$ giây $\left(35 \mathrm{chu} \mathrm{kỳ)} ; 72^{\circ} \mathrm{C} / 10\right.$ phút (1 chu kỳ).

\subsubsection{Phương pháp phát hiện gen kháng kháng sinh bằng kỹ thuật m-PCR}

Các gen blaTEM, blaSHV mã hóa kháng ampicillin; gen strA, strB mã hóa kháng streptomycin; gen tet $\mathrm{A}$, tet $\mathrm{B}$ mã hóa kháng tetracycline và gen sul1, sul2 mã hóa kháng sulfamethoxazole được xác định dựa trên việc sử dụng các cặp môi đặc hiệu tương ứng cho từng gen kháng kháng sinh (Bảng 1).

Thành phần phản ứng m-PCR gồm 2 UI AmpliTaq Gold; 0,2 mM dNTP; 1,5 mM MgCl ; đệm $1 \mathrm{X} ; 0,5 \mu \mathrm{L}$ mỗi đoạn mồi (nồng độ $0,625 \mu \mathrm{M}$ ); $5 \mu \mathrm{L}$ DNA khuôn mẫu và nước cất khử ion vừa đủ thể tích $25 \mu \mathrm{L}$, chương trình khuếch đại trên máy Mastercycler (Eppendorf) như sau: $95^{\circ} \mathrm{C} / 5$ phút (1 chu kỳ); $95^{\circ} \mathrm{C} / 30$ giây; $60^{\circ} \mathrm{C} / 45$ giây và $72^{\circ} \mathrm{C} / 90$ giây $\left(25\right.$ chu kỳ); $68^{\circ} \mathrm{C} / 10$ phút $(1$ chu kỳ). Sản phẩm PCR được kiểm tra bằng phương pháp điện di trên thạch agarose $1 \%$ ở điện thế $100 \mathrm{~V}$ trong thời gian 30 phút và kiểm tra kết quả bằng cách soi dưới đèn UV visualizer. 


\subsection{7. Điện di và đọc kết quả}

Sản phẩm PCR được điện di trên gel agarose $1,5 \%$ có chứa $1 \mu \mathrm{g} / \mathrm{mL}$ ethidium bromide trong TBE. Thang ladder cũng được điện di đông thời. Thời gian điện di là 35 - 40 phút ở $100 \mathrm{~V}$ và $100 \mathrm{~mA}$. Sau đó chụp hình gel với tia UV bằng máy chụp gel Ingenius

Bảng 1. Trinh tự primer sü̉ dụng cho phản ứng PCR

\begin{tabular}{|c|c|c|c|c|}
\hline Mục tiêu & Primer & Trinh tư 5'-3' & Kích thước (bp) & Tham khảo \\
\hline \multirow[t]{2}{*}{$\operatorname{InvA}$} & $\operatorname{Inv} \mathrm{A} 1$ & TTGTTACGGCTATTTTGACCA & \multirow{2}{*}{520} & \multirow{2}{*}[10]{} \\
\hline & $\operatorname{Inv} \mathrm{A} 2$ & CTGACTGCTACCTTGGCTGATG & & \\
\hline \multirow[t]{6}{*}{ Beta-lactam } & blaTEM & GGTCGCCGCATACACTATTCTC & \multirow{2}{*}{372} & \multirow{6}{*}{ [9] } \\
\hline & & TTTATCCGCCTCCATCCAGTC & & \\
\hline & blaSHV & CCAGCAGGATCTGGTGGACTAC & \multirow{2}{*}{231} & \\
\hline & & CCGGGAAGCGCCTCAT & & \\
\hline & blaCTX & CCCATGGTTAAAAAACACTGC & \multirow{2}{*}{950} & \\
\hline & & CAGCGCTTTTGCCGTCTAAG & & \\
\hline \multirow[t]{4}{*}{ Streptomycin } & strA & CCAATCGCAGATAGAAGGC & & \multirow{4}{*}[1]{} \\
\hline & & CTTGGTGATAACGGCAATTC & 608 & \\
\hline & $s t r \mathrm{~B}$ & GGATCGTAGAACATATTGGC & \multirow{2}{*}{256} & \\
\hline & & ATCGTCAAGGGATTGAAACC & & \\
\hline \multirow[t]{4}{*}{ Tetracycline } & tet $\mathrm{A}$ & GGCCTCAATTTCCTGACG & & \multirow{4}{*}{ [3] } \\
\hline & & AAGCAGGATGTAGCCTGTGC & 372 & \\
\hline & tet $\mathrm{B}$ & GAGACGCAATCGAATTCGG & \multirow{2}{*}{228} & \\
\hline & & TTTAGTGGCTATTCTTCCTGCC & & \\
\hline \multirow[t]{4}{*}{ Sulfamethoxazole } & sul1 & TCACCGAGGACTCCTTCTTC & & \multirow{4}{*}[10]{} \\
\hline & & CAGTCCGCCTCAGCAATATC & 331 & \\
\hline & sul2 & CCTGTTTCGTCCGACACAGA & \multirow{2}{*}{435} & \\
\hline & & GAAGCGCAGCCGCAATTCAT & & \\
\hline
\end{tabular}

\section{KẾT QUẢ VÀ BÀN LUẬN}

\subsection{Phân lập và xác định các chủng Salmonella spp.}

Tiến hành phân tích theo ISO 6579-1:2017 và khẳng định bằng kỹ thuật PCR các mẫu thủy hải sản tươi sống được lấy tại các chợ để phát hiện Salmonella spp.. Kết quả được thể hiện ở Bảng 2. Qua đó cho thấy: trong số 380 mẫu được thu thập, phát hiện 85 mẫu có nhiễm Salmonella spp., chiếm tỷ lệ 22,37\% (85/380). Mẫu mực có tỷ lệ nhiễm cao nhất 23,44\% (15/64), tiếp theo là mẫu tôm 22,68\% (22/97) và cuối cùng mẫu cá có tỷ lệ nhiễm thấp nhất với 21,92\% (48/219). 
Bảng 2. Tỷ lệ vấy nhiếm Salmonella spp. phân lập tư thủy hải sản tươi sống

\begin{tabular}{cccccc}
\hline \multirow{2}{*}{ Mẫu } & \multirow{2}{*}{ Tổng số mẫu } & \multicolumn{2}{c}{ Dương tính } & \multicolumn{2}{c}{ Âm tính } \\
\cline { 3 - 6 } & 219 & Số mẫu & Tỷ lệ (\%) & Số mẫu & Tý lệ (\%) \\
\hline \multirow{2}{*}{ Cá } & 97 & 48 & 21,92 & 171 & 78,08 \\
Tôm & 64 & 22 & 22,68 & 75 & 77,32 \\
Mực & 380 & 15 & 23,44 & 49 & 76,56 \\
Tổng số & 85 & 22,37 & 295 & 77,63 \\
\hline
\end{tabular}

\subsection{Kết quả xác định kiểu huyết thanh (serovar) của Salmonella spp. đa kháng}

Các chủng Salmonella spp. sau khi phân lập và xác định được kiểu hình đa kháng, tiến hành xác định kiểu huyết thanh (serovar) của chúng bằng các phản ứng ngưng kết trên phiến kính và trong ống nghiệm, sử dụng kháng huyết thanh $\mathrm{O}$ và $\mathrm{H}$, thực hiện theo ISO/TR 65793:2014 [4]. Kết quả được trình bày ở Bảng 3.

Trong số 13 chủng Salmonella spp. đa kháng, đã xác định được 06 kiểu huyết thanh (serovar), trong đó nhiêuu nhất là kiểu huyết thanh (serovar) S. kentucky (05 chủng); S. infantis (02 chủng); còn lại mỗi chủng cho các kiểu huyết thanh (serovar) S. braenderup, S. potsdam, S. agona và 02 chủng Salmonella có ký hiệu SA07/20 460 và SA07/20 462 phân lập từ mẫu mực, do không nhận diện được kiểu huyết thanh (serovar), (quá trình thử nghiệm ngưng kết với kháng nguyên $\mathrm{H}$ quá trình chuyển pha không xảy ra) nên chỉ ghi nhận công thức kháng huyết thanh.

Bảng 3. Kết quả xác định serovar các chủng Salmonella spp. đa kháng

\begin{tabular}{|c|c|c|c|c|c|c|}
\hline \multirow{3}{*}{$\begin{array}{c}\text { Nguồn } \\
\text { phân lập }\end{array}$} & \multicolumn{3}{|c|}{ Công thức kháng nguyên } & \multirow{3}{*}{ Công thức } & \multirow{3}{*}{ Serovar } & \multirow{3}{*}{ Ký hiệu } \\
\hline & \multirow{2}{*}{$\begin{array}{c}\text { Kháng } \\
\text { nguyên } O\end{array}$} & \multicolumn{2}{|c|}{ Kháng nguyên H } & & & \\
\hline & & Pha 1 & Pha 2 & & & \\
\hline \multirow{8}{*}{ Cá } & 8 & $\mathrm{i}$ & $1, \mathrm{z}_{6}$ & $8: \mathrm{i}: 1, \mathrm{z}_{6}$ & S. kentucky & SA11/19 3514 \\
\hline & 4 & eh & 1,2 & 4:eh:1,2 & S. saintpaul & SA11/19 3515 \\
\hline & 7 & $\mathrm{e}, \mathrm{h}$ & $\mathrm{e}, \mathrm{n}, \mathrm{z}_{15}$ & 7:e,h:e,n, $\mathrm{z}_{15}$ & S. braenderup & SA11/19 4205 \\
\hline & 8 & i & $1, \mathrm{z}_{6}$ & $8: i: 1, z_{6}$ & S. kentucky & SA12/19 501 \\
\hline & 8 & $\mathrm{i}$ & $1, \mathrm{z}_{6}$ & $8: i: 1, z_{6}$ & S. kentucky & SA12/19 1600 \\
\hline & 7 & $1, \mathrm{v}$ & en, $\mathrm{z}_{15}$ & $7:$ L,v:en, $\mathrm{z}_{15}$ & S. potsdam & SA01/20 66 \\
\hline & 8 & $\mathrm{i}$ & $1, \mathrm{z}_{6}$ & $8: \mathrm{i}: 1, \mathrm{z}_{6}$ & S. kentucky & SA02/20 1524 \\
\hline & 7 & $\mathrm{r}$ & 1,5 & $7: 1,5: r$ & S. infantis & SA05/20 210 \\
\hline \multirow{3}{*}{ Tôm } & 4 & $\mathrm{f}, \mathrm{s}, \mathrm{g}$ & & 4:f,s,g & S. agona & SA06/20 1808 \\
\hline & 7 & $\mathrm{r}$ & 1,5 & $7: 1,5: \mathrm{r}$ & S. infantis & SA06/20 1809 \\
\hline & 8 & $\mathrm{i}$ & $1, \mathrm{z}_{6}$ & $8: \mathrm{i}: 1, \mathrm{z}_{6}$ & S. kentucky & SA08/20 2058 \\
\hline \multirow{2}{*}{ Mục } & $\mathrm{OMF}$ & $1, \mathrm{z}_{6}$ & & OMF: $1, \mathrm{z}_{6}: \mathrm{UT}^{\mathrm{a}}$ & - & SA07/20 460 \\
\hline & 7 & $1, \mathrm{z}_{6}$ & & $7: 1, \mathrm{z}_{6}: \mathrm{UT}^{\mathrm{a}}$ & - & SA07/20 462 \\
\hline
\end{tabular}

Ghi chú: a: Không phân loại 


\subsection{Kết quả kháng sinh đồ của các chủng Salmonella spp. phân lập từ thủy hải sản}

Mức độ đề kháng của 85 chủng Salmonella spp. phân lập được với 11 loại kháng sinh thử nghiệm (Bảng 4). Từ đó cho thấy khả năng đề kháng với ít nhất 01 loại kháng sinh của Salmonella spp. chiếm 85,88\% (73/85), kháng từ 02 đến 05 loại kháng sinh 10,59\% (09/85) và từ 06 đến 11 loại kháng sinh 4,71\% (04/85).

Bảng 4. Mức độ kháng kháng sinh của Salmonella spp.

\begin{tabular}{cccc}
\hline Số lượng kháng sinh & \multicolumn{3}{c}{ Tỷ lệ (\%) (n=85) } \\
\cline { 2 - 4 } & Đề kháng & Trung gian & Nhạy cảm \\
\hline Ít nhất 01 kháng sinh & $85,88 \%(73)$ & $52,94 \%(45)$ & $1,33 \%(02)$ \\
Tư 02-05 kháng sinh & $10,59 \%(09)$ & $12,00 \%(18)$ & $22,00 \%(33)$ \\
Từ 06-11 kháng sinh & $4,71 \%(04)$ & $0 \%(00)$ & $62,35 \%(53)$ \\
\hline
\end{tabular}

Bảng 5 cho thấy, tỷ lệ Salmonella spp. kháng nhiều nhất là tetracycline 43,53\% (37/85), kế tiếp là sulfamethoxazole/trimethoprim 35,29\% (30/85). Tỷ lệ kháng tetracycline cao là điều dễ hiểu vì kháng sinh này được sử dụng rộng rãi ở Việt Nam, cả trong điều trị và chăn nuôi [7]. Hơn $98 \%$ số chủng nhạy cảm với ceftazidime. Điều này cho thấy ceftazidime vẫn còn hiệu quả, nên cần phải có hành động nhằm kiểm soát việc sử dụng có hiệu quả loại kháng sinh này.

Bảng 5. Mức độ kháng tùng loại kháng sinh của Salmonella spp.

\begin{tabular}{|c|c|c|c|c|c|c|c|c|}
\hline & \multicolumn{2}{|c|}{ Cá $(n=48)$} & \multicolumn{2}{|c|}{ Tôm $(n=22)$} & \multicolumn{2}{|c|}{$M u ̣ c(n=15)$} & \multicolumn{2}{|c|}{ Chung $(n=85)$} \\
\hline $\begin{array}{l}\text { Kháng } \\
\text { sinh }\end{array}$ & $\begin{array}{l}\text { Số chủng } \\
\text { đề kháng }\end{array}$ & $\%$ & $\begin{array}{l}\text { Số chủng } \\
\text { đề kháng }\end{array}$ & $\%$ & $\begin{array}{l}\text { Số chủng } \\
\text { đề kháng }\end{array}$ & $\%$ & $\begin{array}{l}\text { Số chủng } \\
\text { đề kháng }\end{array}$ & $\%$ \\
\hline $\mathrm{AMC}$ & 01 & 2,08 & 02 & 9,09 & 00 & 0 & 03 & 3,53 \\
\hline $\mathrm{AM}$ & 22 & 45,83 & 01 & 4,55 & 02 & 13,33 & 25 & 29,41 \\
\hline CAZ & 01 & 2,08 & 00 & 0 & 00 & 0 & 01 & 1,18 \\
\hline C & 17 & 35,42 & 00 & 0 & 04 & 26,67 & 21 & 24,71 \\
\hline NA & 19 & 39,58 & 01 & 4,55 & 00 & 0 & 20 & 23,53 \\
\hline CIP & 11 & 22,92 & 01 & 4,55 & 02 & 13,33 & 14 & 16,47 \\
\hline OFX & 07 & 14,58 & 00 & 0 & 00 & 0 & 07 & 8,24 \\
\hline GN & 13 & 27,08 & 00 & 0 & 01 & 6,67 & 14 & 16,47 \\
\hline STR & 19 & 39,58 & 06 & 27,27 & 02 & 13,33 & 27 & 31,76 \\
\hline $\mathrm{TE}$ & 25 & 52,08 & 08 & 36,36 & 04 & 26,67 & 37 & 43,53 \\
\hline SXT & 18 & 37,50 & 10 & 45,45 & 02 & 13,33 & 30 & 35,29 \\
\hline
\end{tabular}

Tỷ lệ Salmonella đa kháng là 15,29\% (13/85). Trong số các chủng đa kháng kiểu hình phổ biến là ampicillin, streptomycin, tetracycline, sulfamethoxazole/trimethoprim (AM, STR, TE, SXT), tỷ lệ 46,15\% (6/13) (Bảng 6). 
Bảng 6. Kiêu hình đa kháng của Salmonella spp.

\begin{tabular}{|c|c|c|c|}
\hline Kýhiệu & Serovar & Kiểu hinh kháng & Số chủng \\
\hline SA11/19 3514 & S. Kentucky & \multirow{6}{*}{ AM, STR, TE, SXT } & \multirow{6}{*}{06} \\
\hline SA11/19 3515 & S. Saintpaul & & \\
\hline SA11/19 4205 & S. Braenderup & & \\
\hline SA12/19 501 & S. Kentucky & & \\
\hline SA05/20 210 & S. Infantis & & \\
\hline SA07/20 462 & $7: 1, \mathrm{z}_{6}: \mathrm{UT}$ & & \\
\hline SA01/20 66 & S. Potsdam & AM, C, NA, CIP, OFX, GN, STR, TE, SXT & 01 \\
\hline SA12/19 1600 & S. Kentucky & AM, TE, SXT & 01 \\
\hline SA02/20 1524 & S. Kentucky & AM, C, NA, GN, STR, TE, SXT & 01 \\
\hline SA06/20 1808 & S. Agona & $\mathrm{AMC}, \mathrm{AM}, \mathrm{C}, \mathrm{NA}$ & 01 \\
\hline SA06/20 1809 & S. Infantis & \multirow{2}{*}{ AM, NA, CIP, GN, STR, TE, SXT } & \multirow{2}{*}{02} \\
\hline SA08/20 2058 & S. Kentucky & & \\
\hline SA07/20 460 & OMF: $1, z_{6}: U T$ & AM, GN, STR, TE, SXT & 01 \\
\hline
\end{tabular}

Chú thích: AMC (Amoxicillin/ Clavunic acid), AM (Ampicillin), C (Chloramphenicol), NA (Nalidixic acid), CIP (Ciprofloxacin), OFX (Ofloxacin), GN (Gentamycin), STR (Streptomycin), TE (Tetracycline), SXT (Sulfamethoxazole/Trimethoprim).

\subsection{Kết quả phát hiện gen đề kháng của các kiểu huyết thanh (serovar)}

Trong số 13 kiểu huyết thanh (serovar) có 92,31\% chủng phát hiện gen đề kháng (blaTEM, strA: $53,85 \%$; blaSHV: 7,69\%; tet A: $92,31 \%$; tet $\mathrm{B}: 7,69 \%$ và sul $1: 23,08 \%)$. 12 trong số 13 chủng có gen tetA mã hóa kháng tetracycline, trong đó có chủng SA01/20 66 (S. potsdam) phát hiện cả hai gen tet $\mathrm{A}$ và tet $\mathrm{B}$, nhưng $\mathrm{SA06/20} 1808$ (S. agona) lại không phát hiện cả hai gen tet $\mathrm{A}$ và tet $\mathrm{B} .13$ chủng hoàn toàn không phát hiện gen bla $\mathrm{CTX}$ và str $\mathrm{B}$. Đối chiếu với kiểu hình hoàn toàn nhạy cảm với ceftazidime vì gen blaCTX không được phát hiện (Bảng 7). Ceftazidime là kháng sinh thuộc nhóm cephalosporin thế hệ thứ 3 . Các $\beta$-lactamase thủy phân nhóm kháng sinh này phân lớn thuộc nhóm CTX, mã hóa bởi gene blaCTX.

Bảng 7. Tỷ lệ các kiêu huyết thanh (serovar) của Salmonella mang gene để kháng kháng sinh

\begin{tabular}{|c|c|c|c|}
\hline Tên kháng sinh & Gen đề kháng & $\begin{array}{c}\text { Số chủng mang gen } \\
\text { đề kháng }\end{array}$ & $\begin{array}{c}\text { Tý lệ (\%) } \\
(n=13)\end{array}$ \\
\hline \multirow{3}{*}{ Ampicillin } & blaTEM & 07 & 53,85 \\
\hline & blaSHV & 01 & 7,69 \\
\hline & blaCTX & 0 & 0 \\
\hline \multirow{2}{*}{ Streptomycin } & $s t r \mathrm{~A}$ & 07 & 53,85 \\
\hline & $s t r \mathrm{~B}$ & 0 & 0 \\
\hline \multirow{2}{*}{ Tetracycline } & tet $\mathrm{A}$ & 12 & 92,31 \\
\hline & tet $\mathrm{B}$ & 01 & 7,69 \\
\hline \multirow{2}{*}{ Sulfamethoxazole } & sul1 & 03 & 23,08 \\
\hline & sul2 & 0 & 0 \\
\hline
\end{tabular}


Trong số 06 kiểu huyết thanh (serovar) có kiểu hình đề kháng AM, STR, TE, SXT, được tiến hành khảo sát kiểu gen, kết quả được trình Bảng 8. Qua đó, chúng tôi phát hiện chỉ có 03 kiểu huyết thanh (serovar) có kiểu gen trùng khớp với kiểu hình đề kháng đó là $S$. kentucky (02) và $S$. Saintpaul (01) đều được phân lập từ mẫu cá.

Bảng 8. Kiêu hình gen đa kháng của Salmonella spp.

\begin{tabular}{|c|c|c|c|}
\hline Ký hiệu & $\begin{array}{c}\text { Kiêu huyết thanh } \\
\text { (serovar) }\end{array}$ & Kiêu hình kháng & Kiểu gen kháng \\
\hline SA11/19 3514 & S. kentucky & & blaTEM, strA, tet A, sul 1 \\
\hline SA11/19 3515 & S. saintpaul & & blaTEM, strA, tet A, sul 1 \\
\hline SA11/19 4205 & S. braenderup & & tetA, sul1 \\
\hline & & AM, STR, TE, SXT & \\
\hline SA12/19 501 & S. kentucky & & blaTEM, strA, tet A, sul 1 \\
\hline SA05/20 210 & S. infantis & & tetA, sul1 \\
\hline SA07/20 462 & $7: 1, z 6: U T$ & & tetA, sul1 \\
\hline
\end{tabular}

Khi so sánh giữa kiểu hình và kiểu gen kháng kháng sinh trên 06 kiểu huyết thanh (serovar) Salmonella spp. đa kháng có cùng kiểu hình (AM, STR, TE, SXT) chúng tôi nhận thấy: các serovar của Salmonella spp. phân lập từ thủy hải sản tươi sống tỷ lệ mang nhiều gen kháng kháng sinh tương ứng cho một kiểu hình kháng kháng sinh là rất thấp. Tuy nhiên, 06 kiểu huyết thanh (serovar) Salmonella spp. đa kháng có cùng kiểu gen không phát hiện các gen blaSHV, $s t r \mathrm{~B}$, tet $\mathrm{B}$ mã hóa cho kháng sinh ampicillin, streptomycin, tetracycline. Mặt khác, 03 kiểu huyết thanh (serovar) tuy có cùng kiểu hình kháng đa kháng sinh nhưng lại không mang đây đủ các gen kháng kháng sinh mã hóa tương ướng.

\section{KẾT LUẬN}

Mức độ vấy nhiễm Salmonella spp. từ thủy hải sản tươi sống là $22,37 \%$. Khả năng kháng kháng sinh của Salmonella với ít nhất 01 loại kháng sinh (85,88\%), từ 02 đến 05 loại kháng sinh (10,59\%) và từ 06 đến 11 loại kháng sinh (4,71\%). Tỷ lệ Salmonella đa kháng là 15,29\%, kiểu hình kháng kháng sinh phổ biến là AM, STR, TE, SXT (46,15\%). Tetracycline có tỷ lệ kháng cao nhất 43,53\%. Định danh được 06 kiểu huyết thanh (serovar) khác nhau, phổ biến nhất là $S$. kentucky (05 chủng); S. infantis (02 chủng); S. agona và S. potsdam (01 chủng); S. saintpaul, S. braenderup (01 chủng). Phát hiện 92,31\% kiểu huyết thanh (serovar) có gen đề kháng (blaTEM, strA: 53,85\%; blaSHV: 7,69\%; tetA: 92,31\%; tetB: 7,69\% và sul1:23,08\%); chỉ có 03 kiểu huyết thanh (serovar) có kiểu gen (blaTEM, strA, tet $\mathrm{A}$, sul1) trùng khớp với kiểu hình đê kháng (AM, STR, TE, SXT) đó là $S$. kentucky (02) và $S$. Saintpaul (01) đều được phân lập từ mẫu cá. Để đảm bảo an toàn vệ sinh thực phẩm và giảm khả năng vấy nhiễm các vi sinh vật kháng kháng sinh cần tăng cường giám sát hiệu quả việc sử dụng kháng sinh trong nuôi trông và chế biến. Cần có những nghiên cứu tiếp theo về dịch tễ học phân tử của các gen kháng kháng kháng sinh của các vi sinh vật lây truyền bằng đường thực phẩm. 


\section{LỜI CẢM ƠN}

Nghiên cứu này được hỗ trợ về kinh phí từ Nhiệm vụ Khoa học Công nghệ theo Hợp đông số 70/2019/HĐ-QPTKHCN.

\section{TÀI LIỆU THAM KHẢO}

[1]. A. Doosti, E. Mahmoudi, M. S. Jami, A. M. Farsani, "Prevalence of aadA1, aadA2, aadB, strA and $s t r \mathrm{~B}$ genes and their associations with multidrug resistance phenotype in Salmonella Typhimurium isolated from poultry carcasses," The Thai Veterinary Medicine, vol 46, no. 4, pp. 691-697, 2016.

[2]. CLSI, Performance Standards for Antimicrobial Susceptibility Testing. 28th ed. CLSI supplement M100. Wayne, PA: Clinical and Laboratory Standards Institute.

[3]. G. Guillaume, D. Verbrugge, M. C. Libotte, W. Moens, J. Collard, "PCR typing of tetracycline resistance determinants (Tet A-E) in Salmonella enterica serotype Hadar and in the microbial community of activated sludges from hospital and urban wastewater treatment facilities in Belgium," FEMS Microbiology Ecology, vol. 32, pp. 77-85, 2000.

[4]. ISO/TR 6579-3:2014, Microbiology of the food chain - Horizontal method for the detection, enumeration and serotyping of Salmonella - Part 3: Guidelines for serotyping of Salmonella spp..

[5]. ISO 6579-1:2017, Microbiology of the food chain - Horizontal method for the detection, enumeration and serotyping of Salmonella - Part 1: Detection of Salmonella spp..

[6]. Lê Văn $\mathrm{Du}, \mathrm{Hô}$ Thị Kim Hoa, “Tình hình tồn dư chất tạo nạc, kháng sinh và nhiễm Salmonella trong thịt heo và gà tiêu thụ tại thành phố Hồ Chí Minh," Tạp chí Khoa học Kỹ thuật Nông lâm nghiệp, tập 5, tr. 46-55, 2017.

[7]. Nguyễn Thanh Việt, Nghiêm Ngọc Minh, Võ Thị Bích Thuỷ, "Nghiên cứu đặc điểm kháng kháng sinh của vi khuẩn Salmonella phân lập từ mẫu thịt lợn, thịt bò và thịt gà tại các chợ bán lẻ tại Hà Nội," Tạp chí Công nghệ Sinh học, tập 16, số 3, tr. 553-564, 2018.

[8]. Quyết định 2625/QĐ-BNN-TY, Kế hoạch hành động quốc gia về quản lý sử dụng kháng sinh và phòng chống kháng kháng sinh trong sản xuất chăn nuôi và nuôi trồng thủy sản giai đoạn 2017-2020, Bộ Nông nghiệp và Phát triên Nông thôn, 2017.

[9]. L. Q. Phong, S. Ueda, N. T. N. Hue, D. T. V. Khanh, H. T. A. Van, T. T. T. Nga, I. Hirai, T. Nakayama, R. Kawahara, D. T. Hung, V. Q. Mai, and Y. Yamamoto, "Characteristics of extended-spectrum $\beta$-Lactamase producing Escherichia coli in retail meats and shrimp at a local market in Vietnam," Foodborne Pathogens and Disease, vol. 12, 2015.

[10]. S. Chen, S. Zhao, D. G. White, C. M. Schroeder, R. Lu, H. Yang, P. F. McDermott, S. Ayers, and J. Meng, "Characterization of Multiple-Antimicrobial-Resistant Salmonella Serovars Isolated from Retail Meats," Applied and Environmental Microbiology, vol 70, no. 1, pp. 1-7, 2004.

[11]. TCVN 8342:2010, Thủy sản và sản phẩm thủy sản - Phát hiện Salmonella bằng kỹ thuật phản ửng chuỗi polymeraza (PCR), 2010.

[12]. Thông tư 14/2011/TT-BYT, Hướng dẫn chung về lấy mẫu thực phẩm phục vụ thanh tra, kiểm tra chất lượng, vệ sinh an toàn thực phẩm. Bộ Y tế, 2011. 


\title{
Investigation into infectability and antimicrobial susceptibility of Salmonella spp. isolated from fresh seafood at traditional markets in Ho Chi Minh city
}

\author{
Truong Huynh Anh Vu ${ }^{1,2}$, Nguyen Hoang Khue Tu ${ }^{3}$, Chu Van Hai ${ }^{1}$ Huynh Yen Ha ${ }^{1}$ \\ ${ }^{1}$ Microbiology laboratory, Center of Analytical Services and Experimentation HCMC (CASE), Vietnam \\ ${ }^{2}$ Biotechnology Department, Nong Lam University of Ho Chi Minh city, Viet Nam \\ ${ }^{3}$ School of Biotechnology, HCMC International University, Vietnam National University \\ of Ho Chi Minh city, Vietnam
}

\section{Abstract}

In this study, a total of 380 fresh seafood samples (fish, shrimp, squid) were collected randomly at conventional markets of districts in Ho Chi Minh city. Salmonella strains were detected by the traditional method (ISO 6579-1:2017) and conformed by PCR technique (TCVN 8342:2010), serotyping according to ISO/TR 6579-3:2014 and Kirby-Bauer methods evaluated antibiotic resistance's ability. As a result, 85 Salmonella strains were isolated, and the proportion of infection was $22,37 \%(85 / 380)$. The proportion of Salmonella strains that resisted 01 antibiotics was $85,88 \%(73 / 85)$, and $10,59 \%(09 / 85)$ accounted for that of strains that resisted 02 to 05 antibiotics. Also, strains representing resistance towards 06 to 11 antibiotics occupied $4,71 \%$ (04/85). Antimicrobial drugs resisted the most were tetracycline $43.53 \%(37 / 85)$. In contrast, $98,82 \%(84 / 85)$ of Salmonella strains were sensitive to ceftazidime. The proportion of multi-drug resistance was $15,29 \%$ (13/85). The familiar combinations of antibiotic resistance were ampicillin, streptomycin, tetracycline, and trimethoprim/sulfamethoxazole (AM, STR, TE, SXT), with 46,15\% (6/13). There were six distinguished serovars, including S. kentucky (05 strains); S. infantis (02 strains); S. agona and S. postdam (01 strain); S. saintpaul, S. braenderup (01 strain). 92.31\% of serovar detected resistance genes (blaTEM, strA: 53.85\%; blaSHV: 7.69\%; tetA: $92.31 \%$; tetB: $7.69 \%$ and sul1: 23.08\%). Three serovars with genotype (blaTEM, strA, tetA, sul1) matched the antibiotic resistance phenotype (AM, STR, TE, SXT), namely S. kentucky (02) and S. saintpaul (01), the both isolated from fish samples.,

Keywords: Multi-drug resistance, antimicrobial resistance, Salmonella, seafood. 